\title{
Evergreen Conventional and Modern Microscopic Methods for Solving Various Cases of Forensic Botany by Morphological and Histological Study
}

\author{
Astha Pandey1, ${ }^{1,}$, Shalvi Agrawal ${ }^{2}$, Amruta D Patel2 ${ }^{2}$, Dushyant Pendarkar², Jalpa D Bambhaniya².
}

\section{Astha Pandey, ${ }^{1, *}$, Shalvi Agrawal $^{2}$, Amruta D Patel ${ }^{2}$, Dushyant Pendarkar², Jalpa D Bambhaniya².}

${ }^{1}$ Assistant Professor, Institute of Forensic Science Gujarat Forensic Sciences University Sector 9, near DFS office, Gandhinagar 382009- Gujarat, INDIA. ${ }^{2}$ Research Scholar, Institute of Forensic Science, Gujarat Forensic Sciences University, Gujarat, INDIA.

\section{Correspondence}

\section{Dr. Astha Pandey}

Asst. Professor, Institute of Forensic Science, Gujarat Forensic Sciences University, Sector 9, near DFS office, Gandhinagar, 382009- Gujarat, INDIA.

Phone no : +91 9601996653

E-mail: aasthapande@gmail.com

\section{History}

- Submission Date: 10-08-2018:

- Review completed: 02-10-2018;

- Accepted Date: 12-12-2018

DOI : 10.5530/pj.2019.1.28

Article Available online

http://www.phcogj.com/v11/i1

\section{Copyright}

(c) 2019 Phcog.Net. This is an openaccess article distributed under the terms of the Creative Commons Attribution 4.0 International license

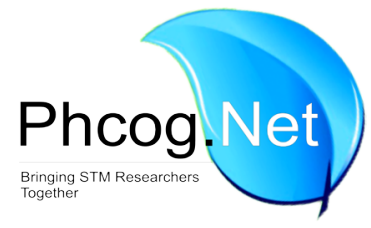

\begin{abstract}
Introduction: The study concerning forensic evidences commences from the physical examination. Microscopic examination serves a good preliminary technique and provides a relatively quick and non-destructive means of obtaining qualitative information without much sample preparation. Various plants or plant materials such as pollens at the crime scene or a rare plant type present near a murder victim can be helpful in connecting suspect to a victim or scene. For examination of such evidences, the initial step is the identification of collected botanical evidences. Scanning electron microscope (SEM) produces images that rely on secondary electrons image and is concerned primarily with the observation of surface topography. SEM images at all direction (X-Y-Z rotation) giving a three dimensional view of the sample under study. Methods: For morphological and histological examination, compound microscope and SEM has been used. Three plant specimens have been taken i.e. Cannabis sativa, Ricinus communis and Papaver somniferum. For compound microscopic examination, sample has been stained with saffranin dye and for SEM examination; sample surface has been coated with gold-palladium layer to make it conductive. Results: The morphological and histological examination by compound microscope and SEM revealed many characteristic features like ellipsoidal pollens in Ricinus, cystolythic trichomes in Cannabis, large oval stomata in poppy, etc. Conclusion: The microscopic examination of botanical evidences by such sophisticated technique like SEM holds a lot of scope in forensic investigations with minimal evidence destruction and maximum details can be obtained in a preliminary examination only without using other complicated techniques.
\end{abstract}

Key words: Botanical evidences, Scanning electron Microscope, Cannabis sativa, Ricinus communis, Papaver somniferum.

\section{INTRODUCTION}

Forensic science helps us in understanding the past i.e. the reconstruction of crime by investigating the site of an ancient massacre and when it comes to solving crime, it is helpful to legal system of course. Across all of these fields, the microscope is an important tool, used to help reconstruct past events. For solving a crime, even trace evidence may make or break a case. For this reason, microscopes are essential in many investigative purposes, because they can magnify an object in great detail. They may be used to check the striations on bullets to determine the type of gun used in a crime or it can also be used to compare hairs, fibers or other particulates recovered from the scene. There are varieties of microscopes used during forensic investigation depending upon the type of evidence gathered from the crime scene. It can be a simple magnifying lens or hand lens or it can be a sophisticated microscope like SEM or Transmission electron microscope (TEM) or Atomic force microscope (AFM).
In forensic investigations, investigators use a variety of microscopes that serves different purposes. The polarized light microscope observes and photographs specimens that are optically anisotropic in character. Polarized light microscopy is capable of providing information on absorption colour and optical path boundaries between minerals of differing refractive indices, in a manner similar to bright field illumination. The technique can also be used to distinguish between isotropic and anisotropic substances. Polarized light microscopy is perhaps best known for its applications in the geological sciences, which focus primarily on the study of minerals in rock thin sections. Polarized light microscope has very limited scope in examination of samples of botanical or biological origin. Comparison microscopy, as the name suggests, is especially useful for the comparison of samples. It can be used for the comparison of hair and fibres, colour and pigment of paint and other polymers and to observe similarities and differences
Cite this article: Pandey A, Agrawal S, Patel AD, Pendarkar D, Bambhaniya JD. Evergreen Conventional and Modern Microscopic Methods for Solving Various Cases of Forensic Botany by Morphological and Histological Study. Pharmacog J. 2019;11(1):171-6 
in a wide variety of other samples. Though it can be used to compare two botanical samples and to identify whether they are similar or different but the magnification ranges between $40 \mathrm{X}$ and $400 \mathrm{X}$ which is very low. Stereo microscopes, also known as dissecting microscopes, are really two compound microscopes which focus on the same point from slightly different angles. This allows the specimen to be viewed in three dimensions thus producing a $3 \mathrm{D}$ image of the specimen. Stereo microscopes are relatively of low power as compared to compound microscopes, usually below 100X. Working distance is much longer than with a typical compound microscope, which allows work to be done on the specimen while it is being observed through the microscope (hence the name "dissecting microscope"). Due to its extremely low magnification power, it is not used much to examine botanical samples.

Out of all the microscopic techniques used by forensic investigators, the application of Scanning Electron Microscope in the field of forensic science is indispensible. No other microscopic technique combines high resolution i.e. up to $2-5 \mathrm{~nm}$ of the secondary electrons with large depth of field for three-dimensional viewing and a magnification up to $1,00,000$ times. ${ }^{1}$ The ability of the SEM in processing each specimen signal by various contrast enhancement methods, such as line scanning, deflection modulation (DM), area mapping, etc., makes it a multipurpose tool. The combination of SEM and energy-dispersive X-ray microanalysis (EDX) is the most extensively used technique in elemental analysis. ${ }^{2}$ In the analyses of other trace evidences also, such as hair and fibres, in physical matching and in non-destructive elemental analysis of physical evidence, the SEM/EDX is the most efficient of all other micro beam technologies. From firearms, bullet wounds and human bones, to plants, pollens, diatoms and fungi, the list of criminal evidence examined by SEM/EDX that can link a suspect to a crime scene, is endless. However, the SEM/ EDX is not ideal for quantitative analysis of elements present as traces $(<1 \% \mathrm{w} / \mathrm{w})$.

\section{MATERIALS AND METHOD}

\section{Anatomical Examination of Root, Stem and Leaf For Compound Microscope Analysis}

For histological study of plant samples, a part of plant like stem or leaf was cut and thin sections from that part was prepared using clean and dry stainless steel blade. The sections were dipped into the pure water first and then were kept for staining in saffranin for few seconds. Then individual section was mounted on clean and dry glass slide with the mounting agent glycerine and was covered with the cover slip properly and remaining drained solution was wiped with tissue paper.

Prepared slide was observed under compound microscope.

\section{For SEM Analysis}

Because the SEM utilizes vacuum conditions and uses electrons to form an image, special preparations must be done to the sample. All water must be removed from the samples because the water would vaporize in the vacuum. All metals are conductive and require no preparation before being used. All non-metals need to be made conductive by covering the sample with a thin layer of conductive material. The specimen was coated with a thin layer of gold-palladium (or other metal) to provide conductivity and some protection from beam damage. Coating thickness could be several nanometre to ten nanometre. After that samples were mounted on the sample holder. Working space was organized and cleaned.

\section{RESULTS AND DISCUSSION}

Figure 1(a), (b), 2(a), (b) and 3(a), (b) shows the transverse section of leaf, stem and root of Ricinus communis. In the figures, we can observe the epidermis which is the outer most layer followed by collenchymatous cells just below the epidermis, which provides mechanical support and also involved in transport of nutrients. Parenchymatous cells are the only photosynthetic cells. When filled with chloroplasts, they are called chlorenchyma. Phloem and xylem are complex tissues that perform transportation of food and water in a plant. They are the vascular tissues of the plant and together form vascular bundles. They work

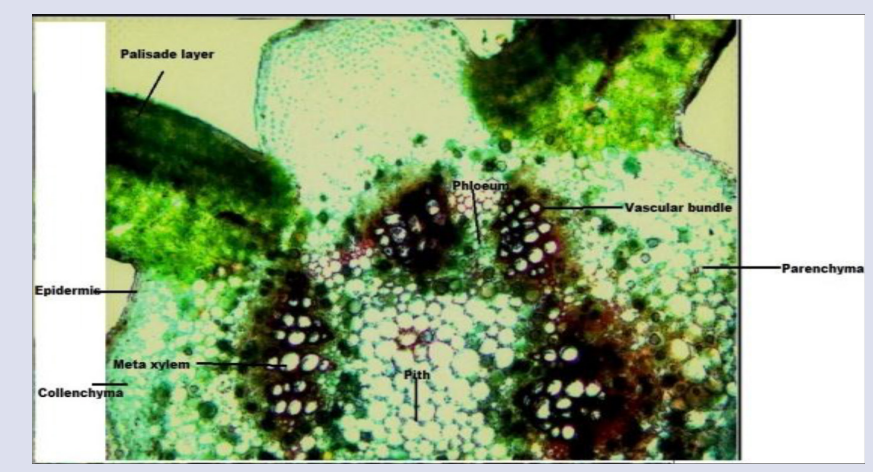

Figure 1(a): T.S. of leaf upper surface of Ricinus communis.

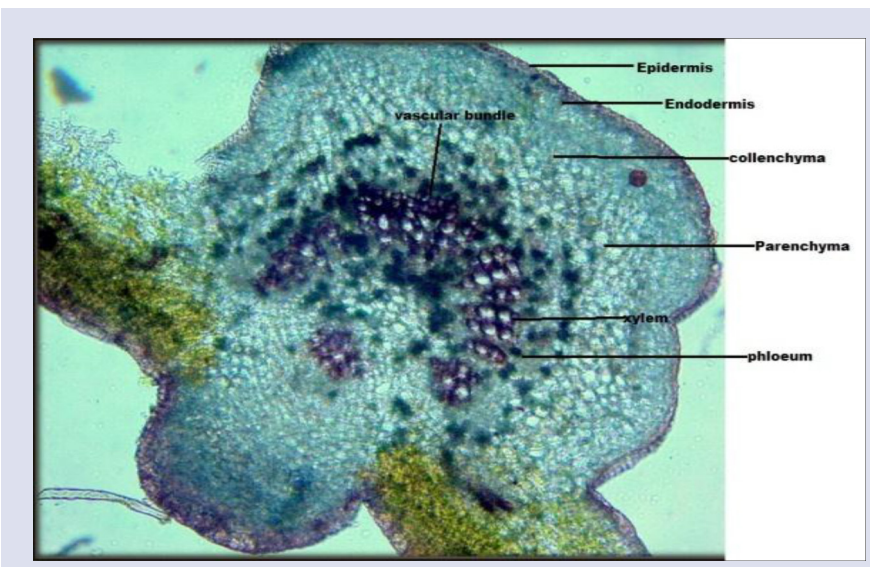

Figure 1(b):T.S. of leaf lower surface of Ricinus communis.

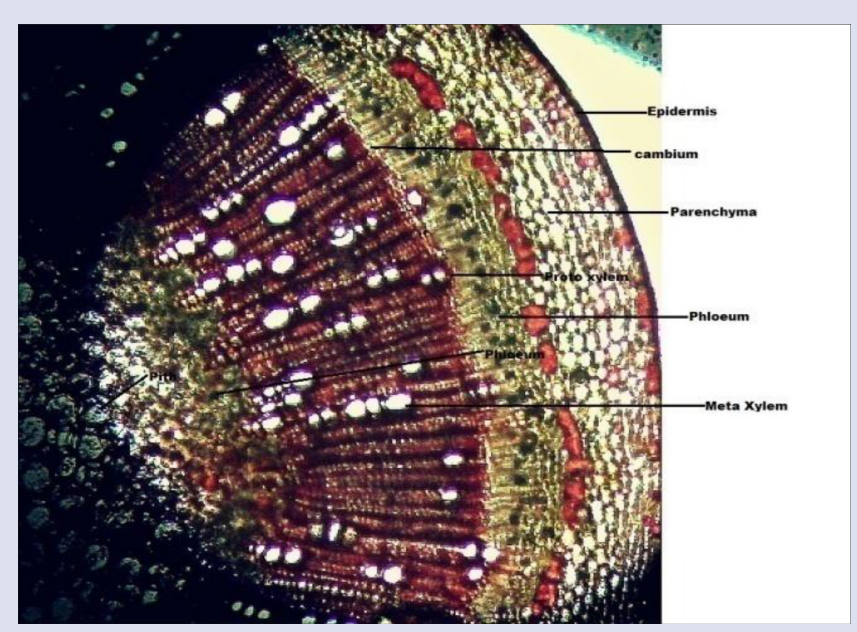

Figure 2(a): T.S. of stem of Ricinus communis. 


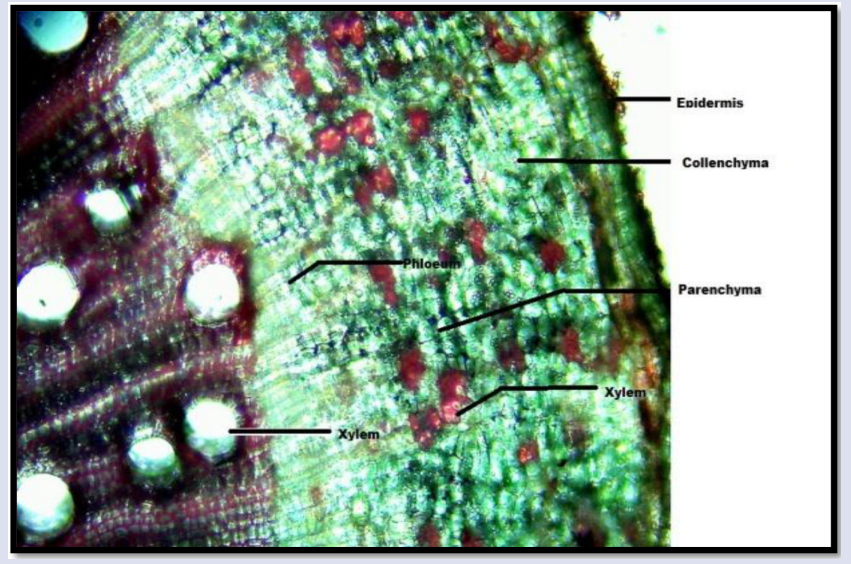

Figure 2(b): T.S. of stem of Ricinus communis

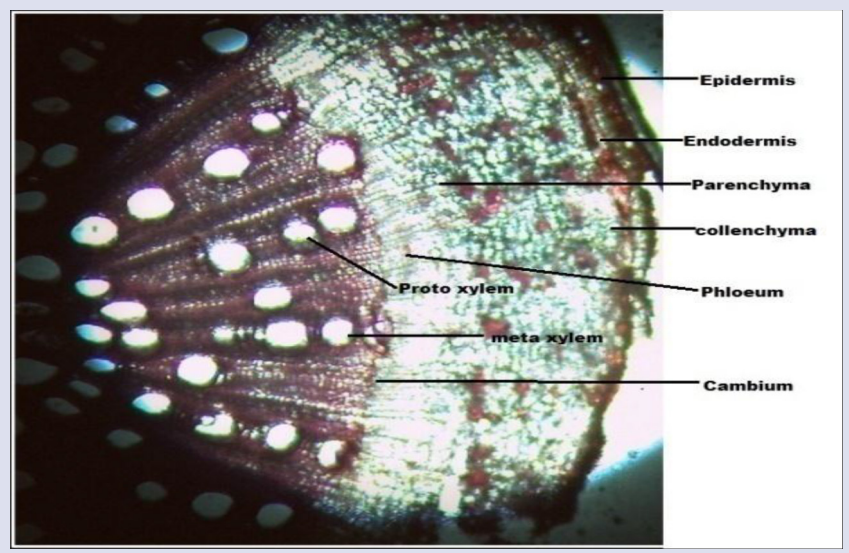

Figure 3(a): T.S. of root of Ricinus communis.

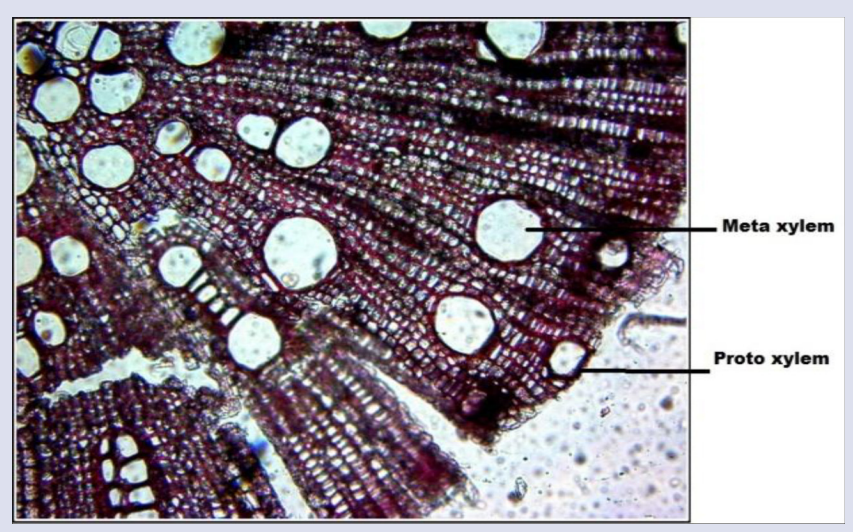

Figure 3(b): T.S. of root of Ricinus communis. together as a unit to bring about effective transportation of food, nutrients, minerals and water. Phloem occurs on outer side of the vascular bundle whereas xylem occupies the centre of the vascular bundle. Xylem is star shaped whereas phloem is not. Pith is a term used to refer to a spongy, usually soft, substance that is found in the middle of the stems and roots of many plants. Another name for this tissue is the medulla. Cambium is a layer of material inside a plant or tree which consists of actively dividing cells which is responsible for secondary growth in the plant. The cambium is filled with undifferentiated cells which have the ability to differentiate into many different types of cells, depending on where in the plant they are growing. ${ }^{3}$

Figure 4 (a), (b) and 5(a), (b) shows the SEM images of upper and lower leaf surface of Ricinus communis in which there is the presence of prominent stomata surrounded by fibrous tissues. ${ }^{4}$

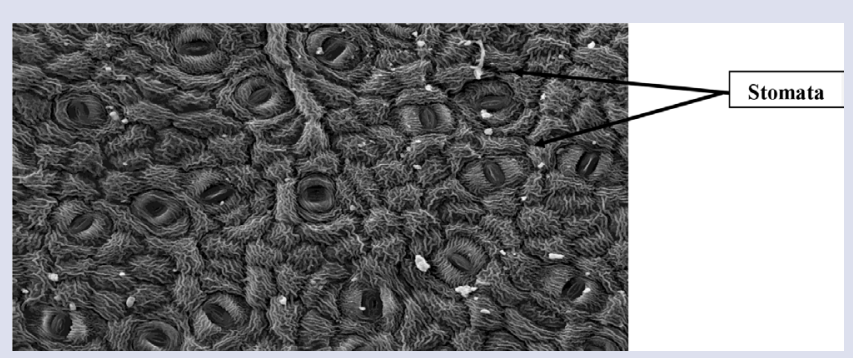

Figure 4(a): SEM image of upper leaf surface of Ricinus.

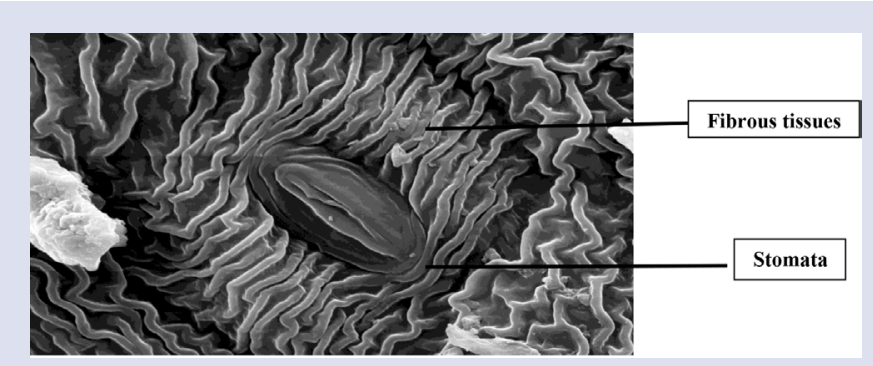

Figure 4(b): SEM image of upper leaf surface of Ricinus showing prominent stomata.

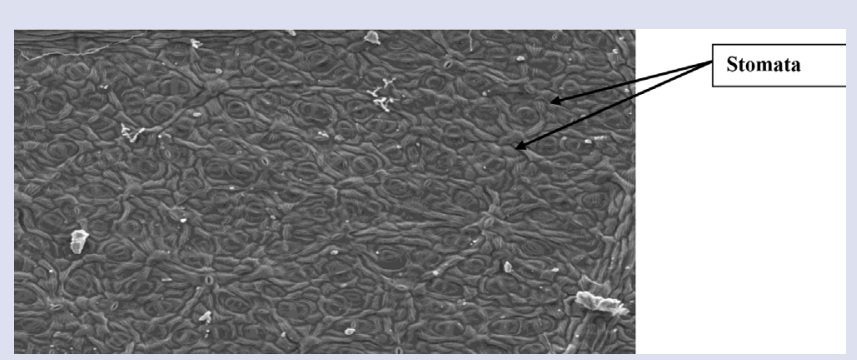

Figure 5(a): SEM image of lower leaf surface of Ricinus showing large number of stomata. 


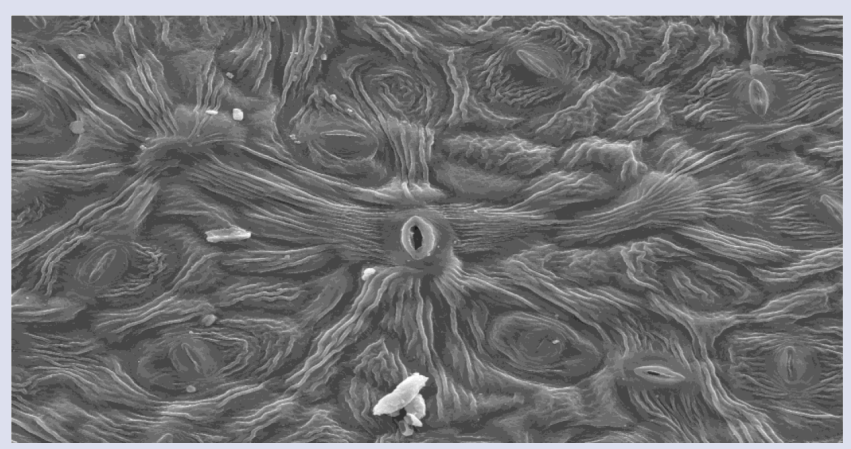

Figure 5(b): Magnified SEM image of lower leaf surface of Ricinus.

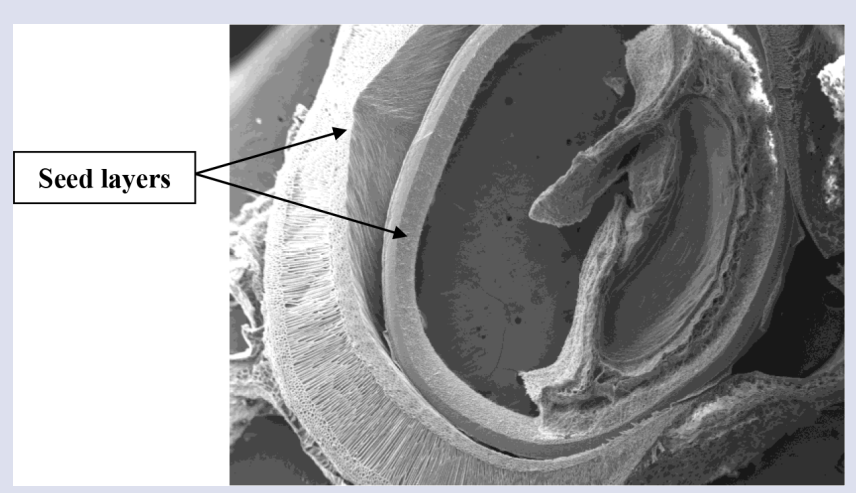

Figure 6: SEM image of Ricinus seed layers.

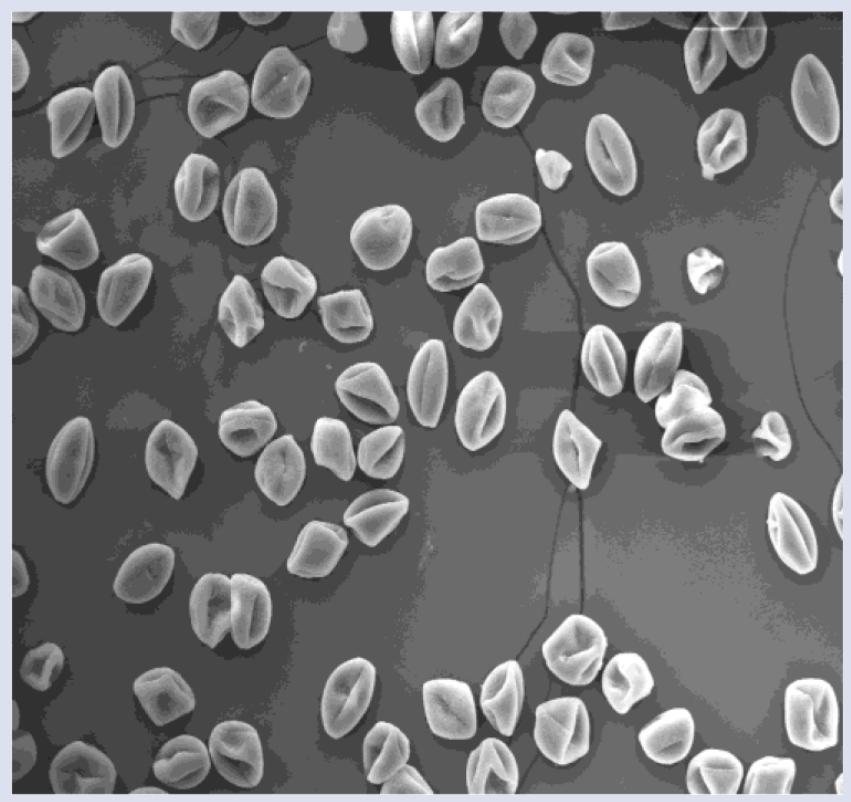

Figure 7(a): SEM image of Ricinus pollens.

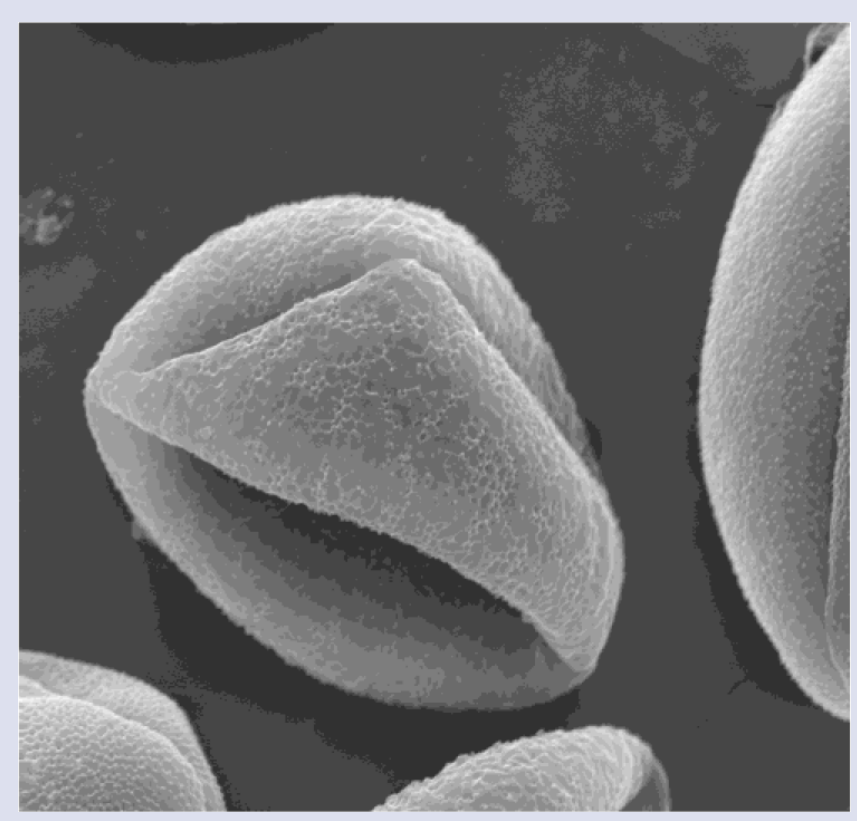

Figure 7(b): SEM image of Ricinus pollen.

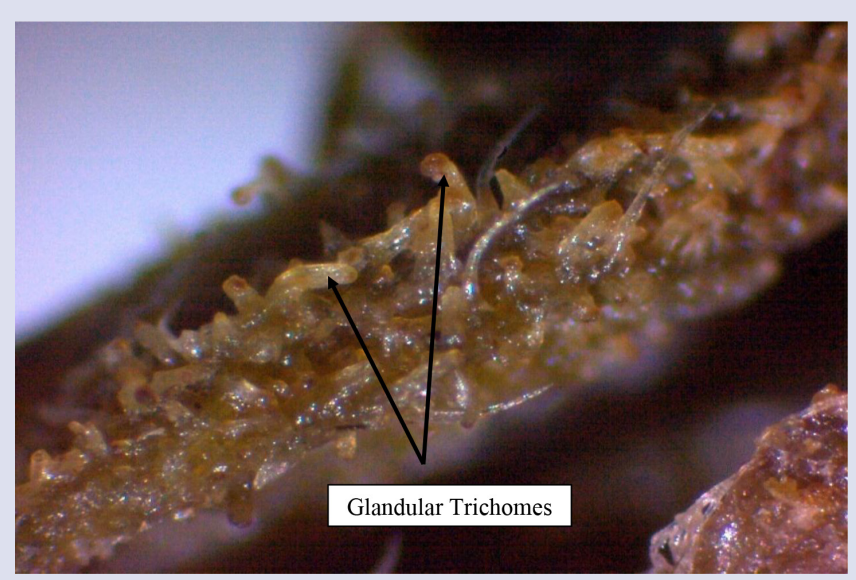

Figure 8(a): T.S. of upper leaf surface of Cannabis.

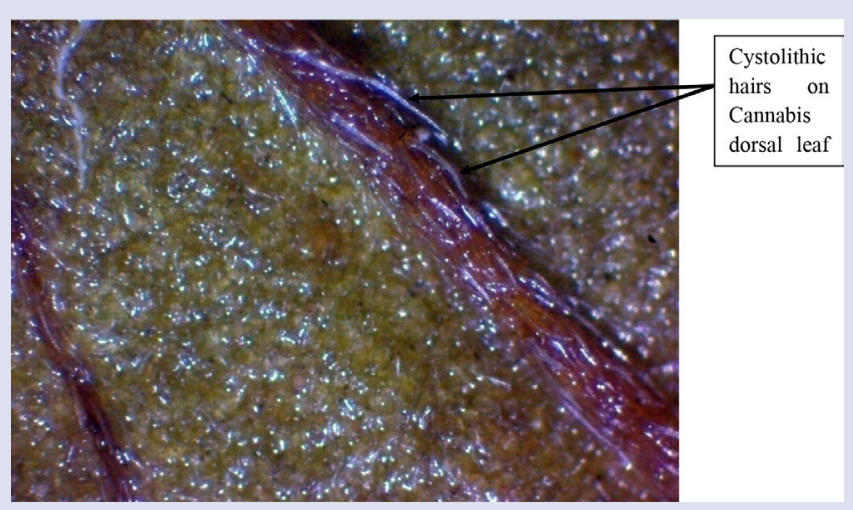

Figure 8(b): T.S. of dorsal leaf surface of Cannabis. 
In Figure 6, different seed layers of Ricinus communis seed can be observed. ${ }^{4}$

Figure 7 (a) and (b) shows the SEM image of R.communis pollen grains. It revealed characteristic features. The pollens were of medium size and were of isopolar, subspheroidal shape with radial symmetry, tectate exines and granulated sexines. ${ }^{5}$

Figure 8 (a) and (b) shows the microscopic examination of Cannabis leaves in which, cystolythic and glandular, unicellular trichomes on both the surfaces can be seen.

Figure 9 shows the microscopic study of transverse section of Cannabis stalk in which the characteristics of dicotyledonous plant can be observed. Cuticle is observed on which hairs are present. Regular and radial pattern of cortex and xylem, phloem can be observed. ${ }^{6-7}$

Figure 10 (a) and (b) shows the presence of characteristic unicellular, non-glandular trichomes of Cannabis. ${ }^{8}$

Figure 10 (c) shows the presence of cystolythic, non-bulbous trichomes of Cannabis. ${ }^{8}$

Figure 11 shows the presence of stomata in the dried opium poppy straw and also some irregular bulbous structures can be seen.

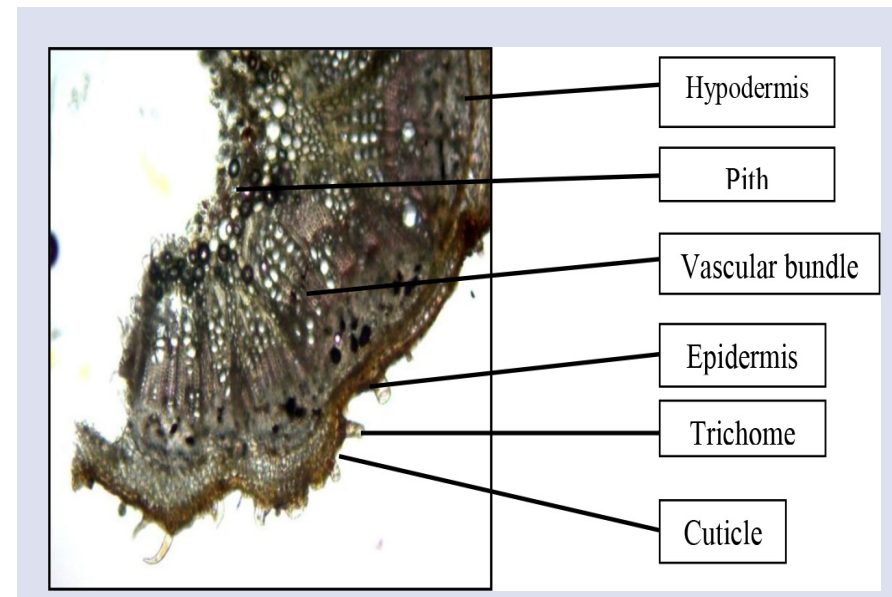

Figure 9: T.S. of Cannabis stalk.

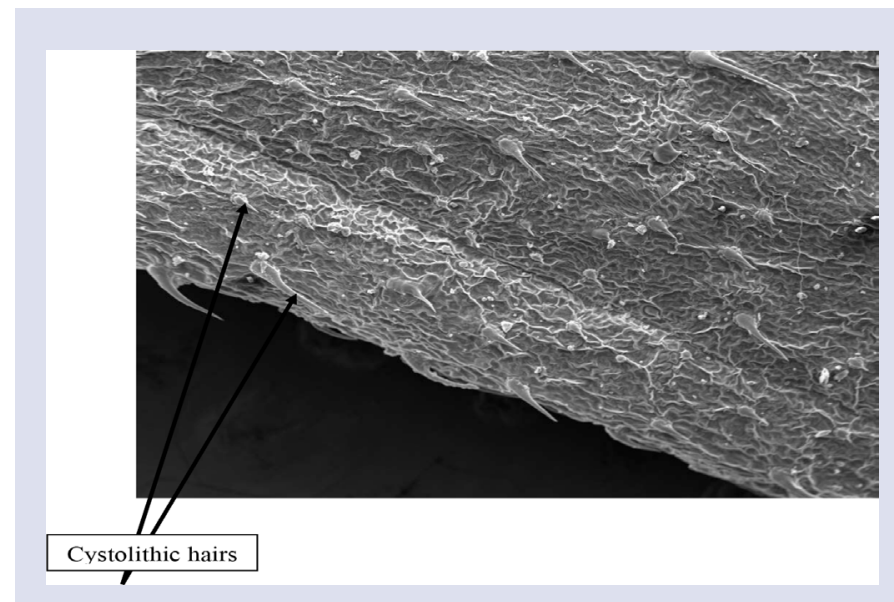

Figure 10(a): SEM image of non-glandular trichomes of Cannabis.

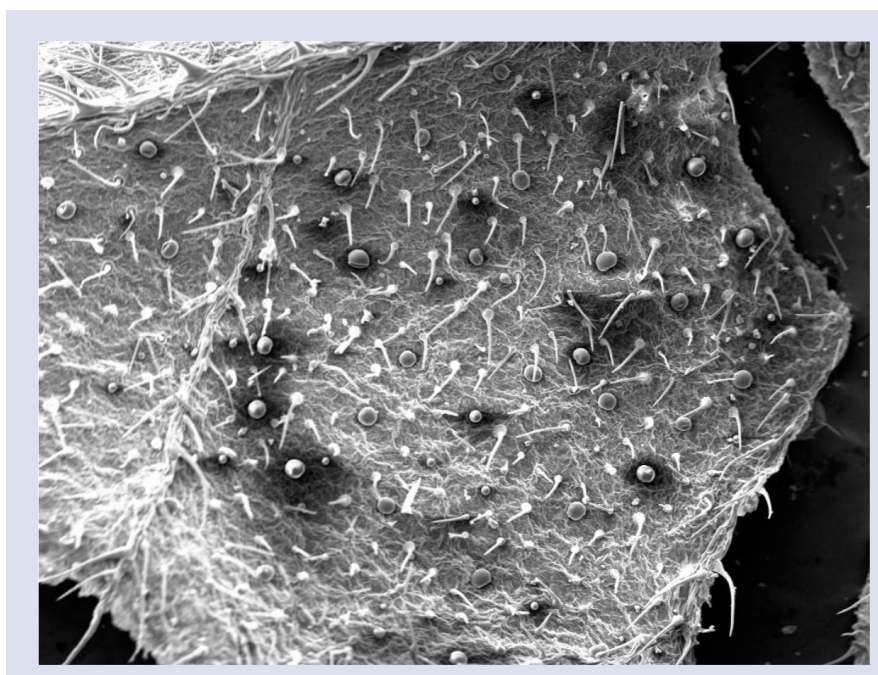

Figure 10(b): SEM image of unicellular non-glandular trichomes of Cannabis.

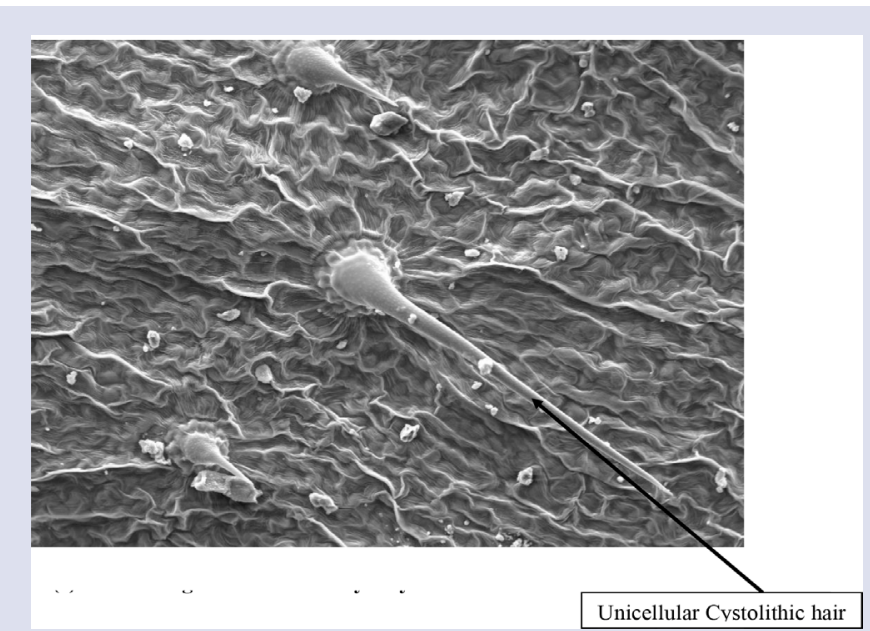

Figure 10(c): SEM image of unicellular cystolythic hair of Cannabis.

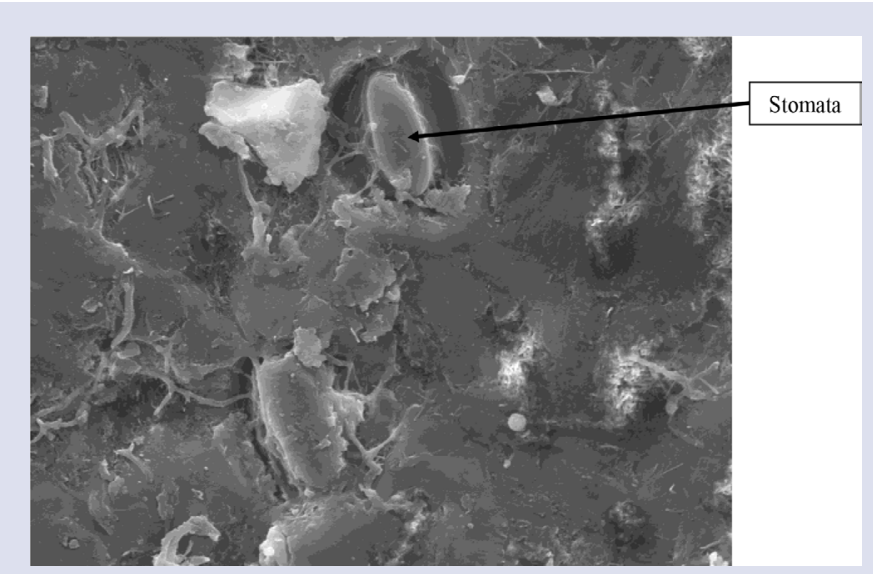

Figure 11: SEM image of dried poppy straw. 


\section{CONCLUSION}

The ability of SEM to provide both high resolution imaging and compositional analysis makes it an excellent tool for forensic investigations. It is already well established for applications such as the analysis of gunshot residue, shooting distance, tool marks and trace evidence. It saves a lot of time by avoiding use of other complicated techniques which are destructible in nature and have lengthy procedures too. It holds a bright future for the use in imaging of botanical samples also like other samples.

\section{ACKNOWLEDGEMENT}

The authors are thankful to the Directorate of Forensic Science, Gandhinagar, Gujarat, for supporting this work during case study.

\section{CONFLICT OF INTEREST}

The authors declare no conflict of interest.

\section{ABBREVIATIONS}

SEM: Scanning Electron Microscope; TEM: Transmission Electron Microscope; AFM: Atomic Force Microscope; DM: Deflection Modulation; EDX: Energy Dispersive X-ray; TS: Transverse Section.

\section{SUMMARY}

Three plant samples have been selected for morphological and histological examination i.e. Ricinus Communis, Cannabis sativa and Papaver somniferum. Their examination was done using compound microscope and scanning electron microscope. Both the techniques gave good results and showed many characteristic features that can be helpful in identification of these plants. The techniques were non- destructive and used very minute amount of samples and hence remaining samples can be utilized for further analysis.

\section{REFERENCES}

1. Basu, S. Scanning Electron Microscopy in Forensic Science. Encyclopaedia of Analytical Chemistry. 2006.

2. Kruesemann H. Innovations in Scanning Electron Microscopy Preserve Sample Integrity and Validity in Forensic Analysis.

3. Bibi H, Afzal M, Kamal M, Rahman IU. Morphological and Anatomical Characteristics of Selected Dicot Xerophytes of District Karak, Khyber Pakhtunkhwa, Pakistan. Middle East Journal of Scientific Research. 2015;23(4):545-57.

4. Shaheen AM. Morphological Variation within Ricinus communis L. in Egypt: Fruit, Leaf, Seed and Pollen. Pakistan Journal of Biological Sciences. 2002;5(11):1202-6.

5. Diamantino MS, et al. Morphology and viability of castor bean genotypes pollen grains. Acta Scientiarum. Agronomy Maringá. 2016;38(1):77-83.

6. Clarke CR, Watson DP. Botany of natural Cannabis medicines. The Haword Interactive Healing Press. 2002;3-13.

7. Srivastava A, Yadav VK. Microscopical and Chemical Study of Cannabis sativa J Forensic Res. 2013;5(1):210.

8. Andre CM, Hausman JF, Guerriero G. Cannabis sativa: The Plant of the Thousand and One Molecules. Front Plant Sci. 2016;7:19.

Cite this article: Pandey A, Agrawal S, Patel AD, Pendarkar D, Bambhaniya JD. Evergreen Conventional and Modern Microscopic Methods for Solving Various Cases of Forensic Botany by Morphological and Histological Study. Pharmacog J. 2019;11(1):171-6. 